\title{
DIÁRIO DE UM ANO INCERTO: REPRESENTAÇÕES DO TEMPO EM 1984, DE GEORGE ORWELL
}

\section{DIARY OF AN UNCERTAIN YEAR: REPRESENTATIONS OF TIME IN GEORGE ORWELL'S Nineteen Eighty-Four}

\author{
André Cabral de Almeida Cardoso ${ }^{1}$
}

\begin{abstract}
RESUMO: Para além da vigilância e da opressão, um elemento central do mundo distópico de 1984 é a contínua reescritura do passado e a tentativa de criar um presente sem fim em que o domínio do Partido seria eterno. No entanto, o passado continua a surgir para assombrar o presente através das lembranças pessoais de Winston Smith, o protagonista do romance, ou na própria crença do Partido de que o passado define o futuro. O objetivo deste artigo é examinar como algumas convenções do gótico são rearticuladas em 1984 para dar forma a representações do tempo ligadas ao ocultamento e à fantasmagoria, que, por sua vez, apontam para os problemas associados a uma temporalidade moderna.
\end{abstract}

PALAVRAS-CHAVE: temporalidade; modernidade; gótico; distopia

\begin{abstract}
Besides constant surveillance and oppression, a central aspect of the dystopian world of Nineteen Eighty-Four is the continuous rewriting of the past and the attempt to create an endless present in which the rule of the Party would last forever. The past nevertheless keeps coming back to haunt the present through Winston Smith's personal memories or in the Party's belief that the past defines the future. The aim of this article is to investigate how some conventions of the gothic are rearticulated in Nineteen Eighty-Four in order to bring forth representations of time related to concealment and phantasmagoria, which point, in their turn, to problems associated with a modern form of temporality.
\end{abstract}

KEYWORDS: temporality; modernity; gothic; dystopia

\section{Introdução}

1984 se abre com uma dupla marcação do tempo: a primeira frase do romance nos informa que a ação se inicia às treze horas de uma fria tarde de abril. Algumas páginas

\footnotetext{
1 Doutor em Literatura Comparada pelo Departamento de Literatura Comparada da New York University. Professor do Departamento de Letras Estrangeiras Modernas da UFF.
} 
adiante, porém, há uma inscrição mais precisa da data. Ao se sentar para começar o seu diário, Winston Smith, o protagonista da narrativa, escreve no topo do "belo papel creme" do caderno antigo comprado por impulso: "4 de abril de 1984” (ORWELL, 2009, p. 16-17). No entanto, Winston logo é tomado por uma sensação de desamparo, pois não pode ter certeza de que aquele é o ano correto. Assim, um ano que se tornaria icônico no imaginário ocidental graças à obra de Orwell surge envolto em dúvida - 1984 pode não ser 1984.

Boa parte do resto da narrativa tentará explicar os motivos dessa incerteza e suas consequências. O vasto Estado totalitário descrito por Orwell promove uma sistemática reescritura do passado, de tal forma que a própria tessitura do tempo se esgarça - essa, aliás, é uma das bases da distopia delineada no romance. Por isso, a maneira como se dá a marcação temporal nas primeiras páginas de 1984 é significativa. O registro preciso do tempo é logo seguido pela hesitação, num movimento que reverbera por toda a estrutura formal do romance. O estilo conscientemente simples e claro de Orwell não impede a proliferação da ambiguidade em seu texto, nem a multiplicação de interpretações muitas vezes opostas por parte de seus críticos, tornando o romance uma espécie de teste de Rorschach literário, nas palavras de Ian Williams (2017, p. 9-10). ${ }^{2}$ Datar o diário é um ato banal, mas traz consequências importantes, pois força Winston a se situar num desenvolvimento histórico que terá de tentar reconstituir. Ao mesmo tempo, levanta a importante questão de a quem se dirigem os seus escritos - Winston chega à conclusão de que eles se dirigem ao futuro, ainda que tenha certeza de que escrever será um exercício inútil, pois o futuro ou será parecido com o presente, e nesse caso ninguém lhe dará ouvidos, ou será diferente, e então a situação em que se encontra será incompreensível (ORWELL, 2001, p. 9). Ou seja, a passagem do tempo implica tensão e isolamento.

Em "O gótico e a presença fantasmagórica do passado", Júlio França aponta que a literatura gótica surge num "momento crítico da história ocidental, em que ocorre uma revolução no entendimento e na percepção do tempo". O final do século XVIII, quando o gótico se consolida como um modo de escrita reconhecível, se caracterizou por uma percepção de que o tempo se acelerava, de que o futuro seria fundamentalmente diferente do presente e de que os eventos do passado eram únicos e não podiam mais se repetir, perdendo sua capacidade de explicar o presente ou de antecipar o futuro. Rompe-se, desse modo, a continuidade entre os tempos históricos. Os eventos do passado, ao tornarem-se estranhos,

\footnotetext{
${ }^{2}$ Williams reclama justamente da dificuldade que os críticos têm de ler o que Orwell de fato escreveu, apesar da clareza de seu estilo (2017, p. 10). Para um ponto de vista semelhante, ver Crick (2007, p. 146). Quanto à importância que o próprio Orwell dava a uma linguagem clara e precisa, ver seu famoso ensaio sobre a política e a língua inglesa (2002, p. 954-967).
} 
tornam-se também potencialmente aterrorizantes e, por isso mesmo, retornam como figurações fantasmagóricas que afetam as ações do presente, ainda que de forma misteriosa (FRANÇA, 2016, p. 2493-2497). Para França, essa forma de temporalidade, somada à caracterização de espaços sombrios e à exploração da monstruosidade, é um dos elementos fundamentais do gótico. França apoia boa parte de sua argumentação na obra de Reinhart Koselleck, que vê nessa criação de uma nova noção de futuro, da visão de um processo histórico essencialmente humano e da ideia de progresso uma verdadeira inversão do nosso horizonte de expectativas, levando ao estabelecimento de uma historicidade propriamente moderna (KOSELLECK, 2004, p. 12-21). A partir daí, torna-se possível apontar para o gótico como um fenômeno moderno, que dá voz às ansiedades geradas pelas novas percepções do tempo a partir do século XVIII (FRANÇA, 2016, p. 2493).

Em 1984, não só o encadeamento do tempo se torna misterioso, como o desamparo de Winston ao datar o seu diário aponta para uma sensação de isolamento radical e de aprisionamento em um presente efetivamente desligado tanto do passado quanto do futuro. Se, num livro recente, Dorian Lynskey descreve o romance de Orwell como um pesadelo gótico (2019, pos. 113), isso se deve não só à atmosfera de ameaça que pesa sobre os personagens e à monstruosidade do Estado totalitário, mas também à própria caracterização do tempo ao longo de toda a obra. Elementos frequentemente explorados pelo gótico, como o ocultamento e a incerteza, a relativização das fronteiras entre ilusão e realidade e a fragilidade do indivíduo diante dos excessos do poder são parte integral da representação do tempo no romance.

A seguir, pretendo discutir a maneira como esses aspectos derivados do gótico dão forma à noção de temporalidade construída em 1984. Longe de serem elementos mais ou menos superficiais que teriam a função de realçar a atmosfera de horror da narrativa, eles são praticamente inescapáveis, pois estão imbricados na visão de mundo expressa pela obra. Sendo assim, também podem ajudar a explicar a ausência de uma saída para o Estado totalitário que muitos críticos de 1984 consideram um defeito do romance, associando-a a uma conformidade do próprio Orwell à inviabilidade de qualquer movimento revolucionário. ${ }^{3}$ Além disso, o caso de 1984 é uma boa indicação de que esses elementos góticos são uma parte integrante do próprio imaginário distópico, visto aqui como uma das maneiras de se refletir sobre a modernidade.

\footnotetext{
${ }^{3}$ Entre esses críticos incluem-se Fredric Jameson (2007, p. 198-202), Tom Moylan (2000, p. 162-163) e Phillip Wegner (2002, p. 216-228). 


\title{
Ocultamento
}

1984 costuma ser associado ao pesadelo da vigilância constante. No entanto, apesar de a vigilância de fato desempenhar um papel fundamental na atmosfera de clausura e medo criada pela narrativa, pode-se argumentar que boa parte da sensação de ameaça que perpassa o livro deriva da manipulação do passado pelo Partido. É essa manipulação que constitui uma das principais ameaças à integridade psíquica de Winston Smith, tornando-se fonte de angústia e perplexidade. Como o próprio Winston reflete, "[s]e o Partido era capaz de meter a mão no passado e afirmar que esta ou aquela ocorrência jamais acontecera - sem dúvida isso era mais aterrorizante do que a mera tortura ou a morte" (ORWELL, 2009, p. 47). A manipulação do passado é essencial para assegurar o projeto de poder do Partido, como explica um trecho do livro que Winston acredita ser de autoria de Emmanuel Goldstein, o principal inimigo do regime, cuja existência, porém, nunca deixa de ser duvidosa:

\begin{abstract}
A mutabilidade do passado é o ponto central da doutrina do Socing. Afirma-se que os fatos passados não têm existência objetiva e que sobrevivem apenas em registros escritos e nas memórias humanas. O passado é tudo aquilo a respeito do que há coincidência entre registros e memórias. Considerando que o Partido mantém absoluto controle sobre todos os registros e sobre todas as mentes de seus membros, decorre que o passado é tudo aquilo que o Partido decide que ele seja. (ORWELL, 2009, p. 251)
\end{abstract}

Hannah Arendt (1979, p. 333) aponta como um dos princípios do totalitarismo justamente a crença de que a história é uma invenção e, portanto, essencialmente manipulável, de que as mentiras mais absurdas podem se tornar fatos inquestionáveis, de que é possível alterar à vontade o passado. Pode-se dizer que essa crença é fundamental para se atingir aquilo que Arendt (1979, p. 361-362) vê como um dos principais objetivos do totalitarismo: a criação de um mundo fictício que obedece a uma coerência interna absoluta. Esse é um dos vários pontos de contato entre a ficção de Orwell e a teoria de Arendt sobre o totalitarismo. No mundo de 1984, não só a história, como também a memória pessoal que em parte lhe dá validade são literalmente uma ficção criada pelo Partido e, portanto, uma criação essencialmente humana. Segundo Koselleck, até boa parte do século XVI, a história no mundo cristão se organizava em torno da expectativa do apocalipse (2004, p. 11). Trata-se de uma visão teleológica da história, que se encontra subsumida ao sagrado. No entanto, como Koselleck argumenta, com a consolidação do absolutismo e o advento das guerras religiosas na Europa, ficou claro que a paz só poderia ser preservada pelos Estados, e não pela Igreja ou por impérios que ainda retinham uma forte função escatológica, como o Sacro Império 
Romano-Germânico - era preciso esvaziar o fator religioso e colocá-lo sob o controle da política. Estabelece-se, assim, uma história humana separada do sagrado. Ao mesmo tempo em que a possibilidade do fim do mundo passa para o domínio da história natural, a história humana deixa de ter um fim pré-determinado (KOSELLECK, 2004, p. 14-16).

Dessa forma, o futuro se abre e se torna imprevisível, ficando ancorado nas ações humanas, e não em um ordenamento divino que dava sentido a todo o desenvolvimento histórico. Essa é uma transformação que, para Koselleck, abre caminho para uma historicidade moderna, num processo que se consolidaria com mais força no século XVIII com o surgimento da noção de progresso (2004, p. 21). O que a argumentação de Koselleck deixa claro, porém, é que essa alteração na nossa própria percepção do tempo não é fruto simplesmente de um movimento mais ou menos espontâneo, uma consequência de novas relações de produção e do desenvolvimento tecnológico, mas tem suas origens num projeto de poder, na busca por hegemonia dos novos Estados modernos. Para Koselleck, o poder está atrelado ao próprio caráter de construção que passa a estar associado à história. Se na história moderna o futuro está aberto, então ele pode ser planejado. A partir do mesmo raciocínio, o passado também pode ser construído, pois a escrita da história poderia ser falsificada e submetida à manipulação (KOSELLECK, 2004, p. 39). O poder, assim, acaba se traduzindo numa tentativa de criar o futuro e, ao mesmo tempo, controlar o passado.

Pode-se dizer, então, que o projeto do Partido de manipular o passado em 1984 surge como corolário de transformações na nossa concepção de historicidade que são marcas da modernidade e que Júlio França, como já vimos, associa a uma visão gótica do tempo em que o passado retorna constantemente para assombrar o presente (2016, p. 2493). Entretanto, como Habermas aponta (1987, p. 5), a busca de um futuro indefinido, o fascínio pelo novo, a sensação de aceleração da história e a vontade de romper com a tradição e se livrar do passado que caracterizam a modernidade acabam levando a uma exaltação de um presente tornado permanente. O processo de radical reescritura do passado representado em 1984 significa, na prática, uma colonização do passado pelo presente, uma imobilização do processo histórico a fim de assegurar que o mesmo grupo social se mantenha eternamente no poder. ${ }^{4}$ Para todos os efeitos, o passado parece desprovido de qualquer capacidade de assombrar o presente, pois sua própria identidade enquanto elemento distinto do presente se encontra ameaçada.

\footnotetext{
${ }^{4}$ Para Pavloski (2014, p. 177, 182), 1984 delineia uma sociedade sem tempo e sem espaço, o que remeteria à etimologia do termo "utopia" como "lugar nenhum"; nesse sentido, a imobilização do fluxo da história promovido pelo governo da Oceânia seria um elemento de crítica satírica ao desejo de estabilidade histórica inerente às utopias clássicas. Kathryn M. Grossman também chama atenção para a fixação no presente como um traço característico da utopia, mas que em 1984 se torna o elemento que faz da narrativa de Orwell uma distopia (1987, p. 52-53).
} 
No entanto, o que o Partido faz não é simplesmente apagar o passado, que não é esquecido nem abandonado. Ao contrário, há uma verdadeira obsessão pelo passado em 1984, que se manifesta de forma bastante clara em um dos lemas do Partido: "Quem controla o passado controla o futuro; quem controla o presente controla o passado" (ORWELL, 2009, p. 47). Longe de acreditar que o passado é irrelevante, o Partido confia plenamente no poder que o passado tem de influenciar o futuro - por isso mesmo ele não deve ser apagado, mas sim constantemente reescrito. A própria recorrência com que todo tipo de registro é trazido à tona para ser reescrito é uma forma de representar de forma paródica o retorno permanente do passado e sua capacidade de assombrar o presente, numa espécie de distorção satírica da noção de temporalidade que torna possível o próprio processo de reescritura do passado. ${ }^{5}$

Trata-se de um processo tortuoso, que encontra uma representação concreta nos corredores labirínticos do Ministério da Verdade, o órgão responsável pela reescritura de todos os registros. O Ministério da Verdade é um espaço desorientador, de uma extensão inimaginável e impossível de mapear, mas ao mesmo tempo claustrofóbico e opressivo, uma vez que, como o castelo gótico (Punter; Byron, 2004, p. 262), é a manifestação concreta do poder. Para Punter e Byron, o castelo gótico encarna um passado que se esconde por trás do momento vivido pelo sujeito e que só pode ser intuído sob o signo do segredo (2004, p. 51). Da mesma forma, no Ministério da Verdade há a evocação velada de um passado que permanece oculto e de uma temporalidade monstruosa, representada pelo "buraco da memória”, o conduto de lixo onde é atirado o material a ser destruído no processo de reescritura dos registros. Na expressão "buraco da memória", a memória passa a figurar seu oposto, o esquecimento, e a passagem do tempo assume mais uma vez o aspecto monstruoso de Cronos devorando seus filhos, na imagem da fornalha que enterra o passado na escuridão.

É fácil perceber, então, que a representação do tempo em 1984 absorve vários elementos típicos do espaço gótico. Boa parte da atmosfera opressiva do romance deriva da sensação de aprisionamento no eterno presente criado pelo Partido. O próprio tempo, dessa forma, acaba se tornando como a cela de uma prisão - nesse sentido, é significativo que a terceira parte da narrativa, que trata do aprisionamento e tortura de Winston, se caracterize pelo sentimento, por parte do personagem, de que o tempo está suspenso, de que ele se encontra em um presente sem fim. Muito antes disso, porém, Winston já tinha a percepção de que tudo ao seu redor desaparecia "num mundo de sombras em que, por fim, até mesmo o ano em que estavam se tornava incerto" (ORWELL, 2009, p. 55-56). A experiência de Winston,

\footnotetext{
${ }^{5}$ Para uma discussão de 1984 como uma sátira - mais especificamente, uma sátira nos moldes de Swift - ver Crick (2007).
} 
portanto, é a de um mundo tomado pela sombra e a obscuridade, como aquele que caracteriza a ficção gótica (BOTTING, 2005, p. 21). ${ }^{6}$ Além disso, o passado insiste em assombrar o presente, apesar de todas as tentativas de subtraí-lo ou controlá-lo: ele está nas casas vitorianas em ruínas e nos prédios decadentes que dão forma à paisagem da cidade, em objetos esquecidos nos bairros operários, como o caderno em que Winston escreve o seu diário, ou em documentos que escaparam ao zelo destruidor do Partido.

Um exemplo desse tipo é a foto que vai parar nas mãos de Winston e que serve de prova objetiva de que o passado fora alterado. A foto mostra três antigos líderes do Partido num encontro oficial no mesmo dia em que deveriam estar numa nação estrangeira traindo o seu governo. Apesar de não causar nenhum impacto nos eventos narrados - ela seria prontamente destruída pelo próprio Winston - a foto adquire uma aura, ficando carregada de um poder evocativo que aponta para o peso do documento como um indício do passado. Em 1984, os raríssimos documentos que evocam o registro histórico e a produção da memória (entre eles incluo o diário do próprio Winston) adquirem uma intensidade especial: eles não são apenas o testemunho de um evento ou de uma época já perdida, são uma encarnação do passado em si. Tanto Botting $(2005$, p. 1,15$)$ quanto Wolfreys $(2002$, p. 8) caracterizam o gótico como uma escrita do excesso - excesso que ambos ligam a um rompimento dos limites do racional e, portanto, a uma problematização da própria possibilidade de representação. Ao revestir os resquícios do passado de uma intensidade que os puxa para o domínio do excesso, Orwell não só sinaliza a importância do conhecimento histórico para se opor ao regime totalitário, como Bellas observa (2020, p. 32), mas também participa de um jogo a que a literatura gótica se dedicou com afinco e que dizia respeito à condição dos documentos do passado, principalmente na forma de manuscritos.

A convenção do manuscrito encontrado tem sido empregada com enorme frequência em textos góticos, quer como peça-chave para o desenlace de diversas situações, quer como elemento gerador da narrativa em si. À primeira vista, a alegação de que o relato a que o leitor tem acesso havia sido encontrado num manuscrito verídico, que o suposto autor do romance não fizera mais do que editar, parece uma tentativa de dar uma maior autenticidade à narrativa. Entretanto, quando Walpole introduz esse recurso na tradição gótica com $O$ castelo de Otranto, ele já era usado há tanto tempo que dificilmente poderia ter o efeito de criar uma

\footnotetext{
${ }^{6}$ João Pedro Bellas (2020, p. 30) chama atenção não só para a manipulação do passado como um elemento de horror gótico central à distopia de 1984, mas a caracteriza como uma operação que torna o passado literalmente incognoscível.
} 
maior sensação de realismo. ${ }^{7}$ Mesmo no caso da primeira edição de Otranto, a alegação de que a obra era a reprodução de um livro publicado em Nápoles em 1529, mas provavelmente escrito ainda antes, tinha menos a função de criar a ilusão de que os eventos que ela narrava eram reais do que a de tornar aceitável, para um público setecentista, a presença de episódios claramente sobrenaturais, que poderiam figurar numa obra já bastante antiga, produzida numa época menos esclarecida, mas que seriam escandalosos numa narrativa moderna (CLERY, 1999, p. 53-54). Como Punter indica (2013, p. 62), a referência a supostos manuscritos encontrados e o entrecruzamento de histórias que vão se validando umas às outras leva à criação de uma "realidade" puramente textual nas obras góticas. Voltando mais uma vez ao exemplo de Otranto, a história tortuosa do manuscrito e as diversas hesitações de seu "editor" a respeito de sua origem chamam atenção para as condições de sua produção e para a sua materialidade enquanto criação textual, ou seja, para a sua possível artificialidade e até mesmo ficcionalidade. Os manuscritos, assim, adquirem uma enorme importância, ao mesmo tempo em que sua natureza é problematizada.

Como a foto descoberta por acaso por Winston, esses textos deteriam um enorme poder como testemunhos do passado, mas são simbolicamente instáveis, ao mesmo tempo presentes e ausentes. Se são símbolos do registro historiográfico, mostram que numa história sem um fim determinado, desvinculada do divino e de qualquer temporalidade que transcenda o plano do puramente humano dentro da qual ela é construída, as pistas para se ter acesso ao passado também são necessariamente fabricadas. Elas mantêm a sua força e o seu fascínio, mas são duvidosas e devem ser interpretadas, pois seu significado não é dado de antemão - a precariedade dos manuscritos evocados pelas obras góticas, frequentemente de autoria incerta, muitas vezes fragmentários e quase ilegíveis, é uma representação disso. A atração do gótico por manuscritos parece ser a tentativa de dar sentido a essa nova percepção dos registros históricos e do desafio de ordená-los num todo coerente.

Para além desses resquícios frágeis, mas eloquentes, o retorno do passado desempenha um papel ainda mais central na narrativa de 1984, já que o regime estabelecido pelo Partido é apresentado como a volta de um passado bárbaro. A idolatria ao Grande Irmão no final dos Dois Minutos de Ódio, por exemplo, é comparada ao canto rítmico de um povo primitivo (ORWELL, 2009, p. 27), enquanto o próprio O’Brien comenta que a tortura com os ratos a que Winston é submetido no final do romance era muito comum na China imperial

\footnotetext{
${ }^{7}$ Nesse sentido, ver Lennard Davis (1986, p. 121-123), que aponta para o caráter altamente convencional desse recurso já nas primeiras décadas do século XVIII, o que tenderia a minar em vez de reforçar a ilusão de realismo que ele supostamente criaria.
} 
(ORWELL, 2009, p. 333). As alusões à pobreza e à sujeira que marcam a vida na Oceânia são um eco das descrições da miséria em regiões coloniais que podemos encontrar em alguns ensaios escritos por Orwell, como "Marrakech", com suas menções a maltrapilhos pedindo pão, guetos medievais e instrumentos pré-históricos (ORWELL, 2002, p. 122-123). Em "Notes on the Way", ensaio publicado em 1940, Orwell se refere a Hitler como "o fantasma do nosso próprio passado se erguendo contra nós" (2002, p. 255; tradução própria) ${ }^{8}$ e, mais adiante no mesmo ensaio, traça uma imagem desalentadora da condição moderna:

É como se num espaço de dez anos tivéssemos caído de volta para a Idade da Pedra. Tipos humanos supostamente extintos há séculos, como o daroês dançarino, o chefe assaltante e o Grande Inquisidor, reapareceram de repente, não como pacientes de um asilo de lunáticos, mas como os mestres do mundo. (2002, p. 257; tradução própria $)^{9}$

Não são poucos os ensaios em que Orwell estabelece uma relação entre o autoritarismo e o ressurgimento de um passado bárbaro. Em "You and the Atom Bomb", o perpétuo presente almejado pelo totalitarismo é comparado à assustadora estabilidade dos impérios escravocratas da Antiguidade (ORWELL, 2002, p. 906), enquanto em "Wells, Hitler and the World State", Orwell evoca um verdadeiro pesadelo: "Criaturas saídas da Idade das Trevas vieram marchando até o presente, e se elas são fantasmas, trata-se de fantasmas que exigem uma forte magia para ser exorcizados" (2002, p. 373; tradução própria). ${ }^{10}$ Esse imaginário propriamente gótico, em que o passado é associado ao monstruoso e ao espectral, dá forma à representação do totalitarismo em 1984, que também é tingida pela experiência do próprio Orwell com o imperialismo britânico, cuja brutalidade ele testemunhara em primeira mão como membro da polícia colonial na Birmânia. O futuro sombrio descrito em 1984 , portanto, está ligado às recordações pessoais do próprio Orwell, que se misturam à história recente de seu país. Entretanto, é justamente nessa interligação do passado histórico com a memória pessoal que se abre um espaço de resistência em 1984.

\section{Resistência}

\footnotetext{
${ }^{8}$ No original: "Hitler is only the ghost of our own past rising against us".

${ }^{9}$ No original: "It is as though in the space of ten years we had slid back into the Stone Age. Human types supposedly extinct for centuries, the dancing dervish, the robber chieftain, the Grand Inquisitor, have suddenly reappeared, not as inmates of lunatic asylums, but as the masters of the world".

${ }^{10}$ No original: "Creatures out of the Dark Ages have come marching into the present, and if they are ghosts they are at any rate ghosts which need a strong magic to lay them".
} 
Em oposição ao processo de apagamento do passado promovido pelo Partido, o que vemos ocorrer ao longo de toda a narrativa de 1984 é o ressurgimento das lembranças pessoais de Winston. Elas parecem resquícios de um passado mais autêntico, por ter sido de fato vivido, ao contrário do passado fabricado pelos dirigentes da Oceânia. São também um refúgio para a individualidade de Winston, aquilo que ele guarda de mais pessoal, ao mesmo tempo em que são a base sobre a qual essa individualidade se estrutura (PAVLOSKI, 2014, p. 173). A entrega a essas lembranças é apresentada, portanto, como um ato de resistência.

No entanto, essas memórias vêm aos poucos, de forma fragmentária, evocadas por associações e sensações, mantendo-se muitas vezes parcialmente ocultas. Desse modo, temos mais uma vez a imagem do passado voltando para assombrar o presente, e a descrição dessas memórias se dá através de uma linguagem que também remete de forma consistente ao fantasmagórico. Pouco depois de ouvir os primeiros versos da canção infantil que ecoaria aos pedaços ao longo da segunda e terceira partes do romance, Winston tem

a impressão de ouvir os sinos; os sinos de uma Londres perdida que ainda existia em algum lugar, disfarçada e esquecida. Um campanário fantasmagórico após o outro, parecia-lhe ouvi-los repicar. Contudo, até onde se lembrava, na vida real nunca ouvira as badaladas de um sino de igreja. (ORWELL, 2009, p. 121)

A cantiga, sobre os sinos das diversas igrejas de Londres - todas relegadas ao desuso -, funciona como um símbolo do poder evocativo do passado e do próprio ato de rememorar. Como podemos ver no exemplo acima, além de serem associadas à fantasmagoria, as lembranças de Winston frequentemente se misturam à sua imaginação e aos seus sonhos, tornando indefiníveis os limites da realidade (PAVLOSKI, 2014, p. 173). Voltamos, assim, a uma atmosfera de indefinição e irrealidade típica do gótico (PUNTER; BYRON, 2004, p. 293-296), que a fragmentação das recordações de Winston torna ainda mais desorientadora: "Não adiantava, ele não conseguia se lembrar. Tudo o que lhe ficara da infância era uma série de tableaux superiluminados, desprovidos de paisagem de fundo e quase sempre ininteligíveis" (ORWELL, 2009, p. 14). O fato de que esses quadros do passado estão sob uma iluminação intensa indica que eles têm uma forte carga emocional, que se torna ainda maior porque eles não estão ligados a um fundo que os ordene e lhes dê uma lógica. Como os documentos que discuti na seção anterior, eles adquirem uma intensidade especial, prometendo um volume de significado que nunca chega a ser completamente revelado.

Pode-se dizer, então, que para Orwell a recordação do passado está investida de um conteúdo emocional e que a memória pessoal está entrelaçada à história social. Por um lado, a falta de registros externos põe em xeque a integridade das lembranças individuais; por outro, 
é só através das lembranças pessoais que a história coletiva pode ser reconstituída e adquirir algum sentido (da mesma forma como o quadro de totalitarismo montado por Orwell em 1984 depende do passado histórico do imperialismo inglês e da experiência pessoal do próprio Orwell nesse contexto). Na contramão desse processo de integração entre o pessoal e o coletivo, o conteúdo das lembranças em si permanece desconectado, sendo percebido como uma série de eventos isolados, em parte por causa da ausência de registros confiáveis, mas também por causa da intensidade que cada lembrança adquire, como se o investimento emocional que cada uma delas recebe exigisse uma atenção quase exclusiva.

Uma das primeiras lembranças de Winston narradas no romance está carregada de uma ressonância emocional desse tipo, e é introduzida como um sonho que ressurge de forma recorrente no relato. $\mathrm{O}$ sonho, na verdade, se resume a uma imagem: a mãe de Winston está sentada em algum lugar subterrâneo, como o fundo de um poço, segurando no colo a irmã do menino (no sonho, Winston sabe que ele tinha uns onze anos na época); as duas olham para cima enquanto afundam cada vez mais, pois agora estão no salão de um navio que naufraga, e vão sendo cobertas pelas águas escuras. O sonho é obviamente uma alegoria do momento em que Winston perdeu a mãe e a irmã, que teriam desaparecido durante um expurgo realizado na década de 1950, quando Winston ainda era criança. O mais interessante aqui é a maneira como essa cena é montada. Fora o gradual afundamento da mãe e da irmã, não há nenhum movimento; por outro lado, o olhar de todos os personagens é representado com uma enorme intensidade, e é nele que se concentra toda a ação dessa sequência. A interposição das águas escuras reforça a potência desse olhar, principalmente da parte de Winston, que continua a enxergar a mãe e a irmã com nitidez apesar do obstáculo. Isso coloca Winston como o principal espectador nessa cena. O sonho traça uma dinâmica da memória em que se privilegia o elemento da visão e na qual a água serve de analogia para o esquecimento como uma força dinâmica que ameaça a persistência da lembrança. Também aponta para o quanto a recordação envolve uma profunda estilização e, portanto, uma estetização da experiência. Esse elemento de estetização fica ainda mais claro quando esse mesmo sonho é retomado um pouco mais adiante, desta vez levando a uma recuperação mais detalhada da lembrança que ele ao mesmo tempo revelava e acobertava - a última vez em que Winston vira a mãe e a irmã no quartinho que a família compartilhava e de onde o menino fugira depois de roubar a porção semanal de chocolate. O que liga o sonho à lembrança agora é o gesto protetor da mãe que cobre a filha com o braço e que Winston já tinha visto em um filme. O sonho começa com elementos que apontam, mais uma vez, para uma intensificação da visão: era um sonho "vasto, luminoso", e "tudo estava inundado de uma luz muito clara e suave que permitia que 
se visse a distâncias intermináveis" (ORWELL, 2009, p. 192). Ao assumir o papel daquele que recorda, Winston de novo é colocado na posição de um espectador que frui uma experiência estética, sendo as imagens luminosas do sonho uma reprodução da tela de cinema, e o gesto da mãe, um traço visual estilizado.

Winston emerge desse sonho com a convicção de que a morte de sua mãe fora trágica de uma forma que não era mais possível, pois a verdadeira tragédia pertencia aos tempos de "antigamente" (ORWELL, 2009, p. 42). Logo em seguida, a narrativa envereda por outro sonho, o primeiro devaneio erótico de Winston com Julia, no qual o gesto da moça ao despirse e atirar a roupa para longe é descrito como um gesto "que também pertencia aos tempos de antigamente". Depois disso, Winston acorda com a palavra "Shakespeare" nos lábios (ORWELL, 2009, p. 43). Essa sequência de sonhos é significativa por vários motivos. Ela explicita a atração de Winston por Julia e, através de uma série de associações, estabelece uma ligação entre a mulher e o passado, que surge agora claramente como um objeto de desejo. O passado torna-se não só o contraponto para o presente, mas também o repositório dos verdadeiros sentimentos humanos e das conexões sociais efetivas.

Para Wegner (2002, p. 196-197), 1984 daria expressão a uma espécie de utopia conservadora, pois Orwell estaria rejeitando qualquer possibilidade de uma transformação radical no futuro - uma vez que qualquer revolução só levaria um novo grupo opressor ao poder - e, juntamente com seu personagem, veria a única alternativa razoável para o Estado totalitário num passado idealizado. Wegner peca aqui ao estabelecer uma equivalência precipitada entre o ponto de vista do personagem e o do autor, mas é inegável que Winston vê o passado como uma alternativa mais atraente ao presente, e sua utopia sem dúvida tem um forte caráter nostálgico - ainda que mesmo essa representação essencialmente positiva do passado deva ser matizada, como pretendo mostrar mais adiante. Entretanto, Wegner (2002, p. 206-208) tem razão ao argumentar que a atração que Winston sente pelo passado é principalmente de natureza estética, e que é através de um julgamento estético que o protagonista de 1984 contrapõe sua ideia do passado de forma positiva ao horror do presente, possibilitando que ele assuma uma postura crítica em relação à realidade que ele vive. Eu acrescentaria que essa sensibilidade estética dá forma à própria experiência que Winston tem do tempo e colabora para a percepção do passado como uma série de eventos isolados, ou seja, como uma sucessão de quadros a serem captados como uma manifestação estética.

O objeto que melhor representa esse apego estético ao passado é o peso de papéis que Winston encontra na mesma loja de quinquilharias em que comprara o caderno onde escreve o seu diário. Como Wegner (2002, p. 206) observa, o que atrai Winston nesse objeto é sua 
aparente falta de utilidade, o que o aproximaria da definição de Kant do objeto estético ao destituí-lo de qualquer função instrumental. Ao mesmo tempo, o peso de papéis se torna uma manifestação física do passado em si, assim como a foto encontrada por Winston que discuti na seção anterior. É por causa de sua condição de objeto estético e representante do passado que o peso de papéis pode entrar numa relação metonímica com o quarto que Winston aluga acima da loja de quinquilharias e que ele passa a usar como um refúgio e o local de seus encontros com Julia.

Nesse quarto, Winston e Julia fazem a ponte entre um passado que parecia melhor e um futuro desejado que estaria livre do Partido; nesse processo, o passado se sobrepõe ao presente, e o quarto passa a configurar um espaço utópico (PAVLOSKI, 2014, p. 207-210). É ali que os dois amantes vivem uma domesticidade que, fora dali, foi destruída pela ausência de privacidade e pelas novas relações familiares impostas pelo Partido, em que o relacionamento íntimo é cuidadosamente regulamentado e os filhos são verdadeiros espiões dos pais. É ali também que Winston e Julia gozam de bens de consumo como café, chocolate, chá, açúcar e maquiagem, obtidos no mercado negro. Esses itens, tornados raros no regime do Socing, também são, de certa forma, resquícios do passado que o leitor prontamente reconhece na sua realidade cotidiana. A presença desses objetos de consumo, somada à decoração vitoriana do quarto e ao destaque dado ao próprio globo de vidro, leva Wegner a ver na constituição desse espaço utópico o retorno nostálgico a um passado inglês "autêntico", ao auge do império britânico, que fornece as condições para a circulação dessas mercadorias. Para Wegner, o passado mais "são" que serve de contraponto à sociedade aterradora criada pelo Partido não seria o presente em que Orwell escreve o romance, mas o passado do próprio Orwell, o de sua infância (2002, p. 207-208, 212). No entanto, é preciso considerarmos até que ponto essa evocação de um passado ao mesmo tempo doméstico e oficial, ligado à pompa de um império perdido, se coaduna com a descrição da loja da qual o quarto é uma extensão. A loja em si é chamada pelo narrador de uma loja de trastes - ou, se traduzirmos literalmente o termo em inglês, uma loja de lixo (junk-shop) (ORWELL, 2001, p. 97) - e é um reflexo do tipo de estabelecimento que Orwell descreve com gosto no ensaio "Just Junk - But Who Could Resist It?”, publicado em 1946. No ensaio, Orwell (2002, p. 983-984) menciona casualmente um peso de papéis com um pedaço de coral envolto no vidro como um dos raros tesouros que podem ser encontrados nessas lojas, sempre atulhadas de objetos sem valor, pois vendem qualquer coisa que não seja perecível, e localizadas em áreas decadentes da cidade, sendo facilmente reconhecíveis pela camada de poeira que cobre a vitrine. O peso de papéis parece representar menos o passado sólido e ordenado do imperialismo vitoriano do que o 
passado sem nexo e pouco respeitável da loja de trastes, formado por uma coleção de elementos reunidos ao acaso, despidos de sentido por estarem desligados de qualquer contexto e dentre os quais é possível escolher por um capricho aqueles que parecem mais atraentes.

Entretanto, há outros aspectos relacionados ao peso de papéis e ao quarto acima da loja que complicam a maneira como eles representam o passado. Kathryn Grossman (1987, p. 57-59) também vê o quarto como um espaço utópico ligado ao passado, porém observa que todas as imagens utópicas de 1984 são ambíguas. Desse modo, o peso de papéis, que concentra tanto do desejo utópico no romance, é associado logo de início à violência e à morte, pois pouco depois de comprá-lo, Winston fantasia que poderia usá-lo como uma arma para assassinar Julia, que a essa altura ele desconfiava ser uma agente da polícia secreta (GROSSMAN, 1987, p. 59). Além disso, em um ponto importante do romance, quando celebra sua aliança com O’Brien, que julga ser um inimigo do Partido como ele, Winston tem uma espécie de visão "em que se misturavam o quarto escuro onde sua mãe passara os últimos dias de sua vida, o comodozinho sobre a loja do sr. Charrington, o peso de papéis de vidro e a gravura de aço com sua moldura de pau-rosa" (ORWELL, 2009, p. 212). Os símbolos positivos do passado surgem novamente nesse trecho, mas desta vez imbuídos de uma atmosfera de ameaça ao serem associados ao quartinho que incorporava o luto pela morte da mãe e da irmã. Além disso, outro importante símbolo do passado no romance, a canção infantil que ressurge de forma recorrente e com tanta nostalgia ao longo da narrativa, se encerra com dois versos terríveis que fazem alusão direta a uma morte violenta: "Vá para a cama e seja um bom moço, ou a cuca vem e te corta o pescoço" (ORWELL, 2009, p. 119). ${ }^{11}$ Esses versos são repetidos para Winston e Julia no momento em que eles são presos no quarto que lhes servia de refúgio. Revela-se, então, que a nostalgia pelo passado era literalmente uma armadilha: o peso de papéis era uma isca, e o quarto havia sido preparado para enredar Winston e Julia. É significativo que uma das últimas cenas em que é evocada a atmosfera de conforto nostálgico no quarto esteja ligada a uma falha de leitura. Trata-se do momento em que Winston inicia sua leitura do livro escrito por Emmanuel Goldstein, um documento histórico de natureza ambígua, pois pode ser tanto uma análise escrita anos antes com o objetivo de denunciar o regime do Socing, quanto uma obra escrita pelo próprio Partido como

\footnotetext{
${ }^{11}$ No texto em inglês, o ato de violência física é apresentado de forma ainda mais explícita: "Here comes a candle to light you to bed, Here comes a chopper to chop off your head" (ORWELL, 2001, p. 102). Uma tradução literal desses versos, sem nenhuma preocupação formal, seria: "Aí vem uma vela para iluminar o caminho até a cama, Aí vem um machado para cortar a sua cabeça”. A imagem da vela conduzindo a criança para a cama realça a traição da decapitação que se segue.
} 
uma espécie de plano de ação e, ao mesmo tempo, uma armadilha para os incautos. A poltrona aconchegante, os pés estendidos sobre o aquecedor, o som dos gritos de crianças brincando ao longe, tudo lembra as primeiras linhas do ensaio "Decline of the English Murder", em que Orwell descreve, com uma certa dose de sarcasmo, o clima ideal para se passar uma tarde de domingo lendo sobre algum assassinato sensacional noticiado no jornal (ORWELL, 2002, p. 1028-1029). A atitude de Winston ao abrir o livro de Goldstein é semelhante à do leitor alienado atrás de crimes sensacionais e não parece adequada para o material que ele tem em mãos, que lhe prometia, ao contrário, o fim da alienação ao revelar o verdadeiro funcionamento de sua sociedade.

O apego excessivo ao passado, assim, seria uma prisão, fruto de uma visão equivocada. Para Winston, o fascinante no peso de papéis

\begin{abstract}
não era o fragmento de coral, mas o próprio interior do vidro. Havia tamanha profundidade ali, e no entanto o vidro era quase tão transparente quanto o ar. Era como se a superfície do vidro fosse o arco do céu, encerrando um mundo minúsculo em sua atmosfera completa. Winston tinha a sensação de que seria capaz de entrar ali e de que na verdade estava ali dentro, ele, a cama de mogno, a mesinha de abas dobráveis, o relógio, a gravura de aço e o próprio peso de papéis. O peso de papéis era o quarto onde ele estava, e o coral era a vida dele e a de Julia, fixadas numa espécie de eternidade no coração do cristal. (ORWELL, 2009, p. 176)
\end{abstract}

Nesse devaneio de Winston, o vidro acaba se transformando na própria substância do tempo. O que fascina Winston, portanto, é a fantasia de fixar o tempo numa eterna permanência. Como Grossman observa, o Partido buscava um mundo imobilizado num presente sem fim, enquanto Winston sonha com um passado igualmente imobilizado. Incapaz de conceber uma utopia dinâmica, Winston tenta escapar da distopia apenas para reproduzir, a partir de outra direção, o projeto distópico da suspensão do tempo (GROSSMAN, 1987, p. 59).

As memórias de Winston e a visão de passado a que dão forma, portanto, se estruturam a partir de elementos representacionais ligados às ideias de fantasmagoria, ilusão, fragmentação, intensidade e ameaça equivalentes às imagens do passado relacionadas ao autoritarismo. Se 1984 não oferece uma saída viável para o totalitarismo do Partido, isso ocorre em parte porque o seu protagonista está preso a uma concepção do tempo semelhante à de seus opressores. Em certo ponto do livro de Goldstein, explica-se que a essência do domínio oligárquico "não é a hereditariedade de pai para filho, mas a persistência de determinada visão de mundo e de um certo estilo de vida impostos pelos mortos sobre os vivos" (ORWELL, 2009, p. 247). Em 1984, portanto, o próprio poder totalitário é fantasmagórico, pois é o perpétuo domínio do passado dos mortos sobre o presente dos vivos. O retorno do passado para assombrar o presente se torna parte da lógica de reprodução do 
sistema distópico e está ligado a um projeto de poder. No entanto, também é parte integrante do projeto moderno de uma historicidade puramente humana, do qual o autoritarismo do Partido é apenas o exemplo mais acabado. A memória é espaço de liberdade em contraponto à realidade controlada pelo Partido; por outro lado, é também armadilha que prende pelo seu fascínio, que se mistura com a ilusão e que nega ao sujeito o sentido almejado, o fim de sua alienação em relação ao próprio passado.

\section{REFERÊNCIAS}

ARENDT, Hannah. The Origins of Totalitarianism. San Diego; Nova York; Londres: Harcourt Brace, 1979.

BELLAS, João Pedro. O gótico, o sublime e a distopia: uma leitura de 1984. Abusões, Rio de Janeiro, v. 12, n. 12, p. 14-44, 2020.

BOTTING, Fred. Gothic. Londres; Nova York: Routledge, 2005.

CLERY, E. J. The Rise of Supernatural Fiction, 1762-1800. Cambridge: Cambridge UP, 1999.

CRICK, Bernard. Nineteen Eighty-Four: Context and Controversy. In: RODDEN, John (Org.). The Cambridge Companion to George Orwell. Cambridge (UK); Nova York: Cambridge UP, 2007. p. 146-159.

DAVIS, Lennard J. A Social History of Fact and Fiction: Authorial Disavowal in the Early English Novel. In: SAID, Edward W. (org.). Literature and Society. Baltimore; Londres: The Johns Hopkins UP, 1986. p. 120-148.

FRANÇA, Júlio. O gótico e a presença fantasmagórica do passado. In: Anais eletrônicos do XV encontro da ABRALIC, v. 1. Rio de Janeiro: Dialogarts, 2016. p. 2492-2502.

GROSSMAN, Kathryn M. "Through a Glass Darkly": Utopian Imagery in Nineteen EightyFour. Utopian Studies, n. 1, p. 52-60, 1987.

HABERMAS, Jürgen. Modernity - An Incomplete Project. In: FOSTER, Hal (org.). The AntiAesthetic: Essays on Postmodern Culture. Seattle: Bay Press, 1987. p. 3-15.

JAMESON, Fredric. Archaeologies of the Future: The Desire Called Utopia and Other Science Fictions. Londres; Nova York: Verso, 2007.

KOSELLECK, Reinhart. Futures Past: On the Semantics of Historical Time. Nova York: Columbia UP, 2004.

LYNSKEY, Dorian. The Ministry of Truth: A Biography of George Orwell's 1984. Edição Kindle. Londres: Picador, 2019. 
MOYLAN, Tom. Scraps of the Untainted Sky: Science Fiction, Utopia, Dystopia. Boulder (CO): Westview Press, 2000.

ORWELL, George. Nineteen Eighty-Four. Londres: The Folio Society, 2001. Essays. Everyman's Library. Nova York; Toronto: Alfred A. Knopf, 2002. 1984. São Paulo: Companhia das Letras, 2009.

PAVLOSKI, Evanir. 1984: a distopia do indivíduo sob controle. Ponta Grossa: UEPG, 2014.

PUNTER, David. The Literature of Terror, vol. 1: The Gothic Tradition. 2. ed. Londres; Nova York: Routledge, 2013.

PUNTER, David; BYRON, Glennis. The Gothic. Malden (MA); Oxford: Blackwell, 2004.

WALPOLE, Horace. The Castle of Otranto. Oxford: Oxford UP, 1998.

WEGNER, Phillip E. Modernity, Nostalgia, and the Ends of Nations in Orwell's Nineteen Eighty-Four. In: Imaginary Communities: Utopia, the Nation, and the Spatial Histories of Modernity. Berkeley; Los Angeles; Londres: U of California P, 2002. p. 183-228.

WILLIAMS, Ian. Political and Cultural Perceptions of George Orwell: British and American Views. Nova York: Palgrave Macmillan, 2017.

WOLFREYS, Julian. Victorian Hauntings: Spectrality, Gothic, the Uncanny and Literature. Basingstoke (UK); Nova York: Palgrave, 2002.

Recebido em 28/9/2020.

Aceito em 12/12/2020. 